\title{
Alejandro Zambra: hacia UNA estéticA de LA CONTENCIÓN en el ChILE CONTEMPorÁNeo
}

\author{
Tomás Peters ${ }^{1}$ \\ Universidad de Chile
}

\begin{abstract}
Resumen: El escritor chileno Alejandro Zambra se ha convertido en los últimos años en una figura emergente en el espacio literario latinoamericano. En Chile, su figura ha logrado amplio reconocimiento y sus trabajos han sido vinculados a una narrativa generacional caracterizada por los paisajes literarios de la post - dictadura chilena, así como también por los cambios culturales surgidos con la globalización. A lo largo de sus libros cortos, novelas y cuentos — Bonsái (2006), La vida privada de los árboles (2007), Formas de Volver a casa (2011), Mis documentos (2013) y Facsímil (2014) — es posible advertir una insistencia por el repliegue hacia lo íntimo, lo contenido, la esfera privada. En base a un análisis sociológico — cultural sobre la individuación de la sociedad actual —y chilena en particular_-, este artículo desarrolla dos hipótesis de lectura sobre los trabajos de Zambra: por una parte, sus pasajes escriturales se comprenderían por las figuras de la privatización biográfica bajo el neoliberalismo chileno. Y, por otra, su escritura podría ser percibida como un ejercicio de análisis para discutir la memoria en Chile. A través del análisis de pasajes específicos de la obra de Zambra, este artículo pone a prueba ambas lógicas de lectura y propone comprenderlas como insumos para una estética de la contención.
\end{abstract}

Palabras clave: individuación; literatura chilena; post_-dictadura; Zambra; contención.

Recibido: 23 octubre de 2018

Aprobado: 26 noviembre de 2018

\section{AlEJANDRO ZAMBRA: TOWARDS AESTHETICS OF CONTAINMENT IN THE CONTEMPORARY CHILE}

Abstract: The Chilean author Alejandro Zambra has become an emergent figure in the Latin American literary milieu in the last years. In Chile, he has achieved wide recognition and his works have been linked with a generational narrative characterized by literary landscapes of the Chilean post - dictatorship, as well as for the current cultural global-

\footnotetext{
${ }^{1}$ Tomás Peters es Sociólogo, Magíster en Teoría e Historia del Arte y Doctor en estudios culturales por Birkbeck, University of London. Investigador Postdoctoral en el Instituto de la Comunicación e Imagen de la Universidad de Chile. Correo electrónico: tpeters@uchile.cl
} 
ization. In his short books, novels and stories - Bonsái (2006), La vida privada de los árboles (2007), Formas de Volver a casa (2011), Mis documentos (2013) y Facsimil (2014) — it is possible to notice a permanent insistence towards intimate, containment, private sphere. Based on a sociological — cultural analysis of the individuation in the current society - and Chilean society in particular-, this article shows two hypotheses on Zambra's novels: on the one hand, his writings describe the biographical privatization under the Chilean neoliberalism. And, on the other hand, his narratives may be perceived as an analytic source for the study of the memory in Chile. Through the analysis of specific passages of Zambra's novels, this article attempts to lay out both hypothesis, and tries to understand both as an aesthetics of containment.

Keywords: individuation; Chilean literature; post-dictatorship; Zambra; containment.

\section{Introducción}

Desde el retorno a la democracia en 1990, en Chile se han producido múltiples transformaciones culturales, sociales y políticas; por lo cual resulta difícil plantear tesis consensuadas de interpretación. Sin embargo, una serie de investigadores y teóricos culturales han caracterizado este periodo por la implantación radical del neoliberalismo (Moulian 1997; Garretón 2000; Larraín 2001) y la emergencia de lo íntimo como una construcción narrativa de la subjetividad post-dictatorial (Amaro; Blanco). Entre la década del noventa y el dos mil, en Chile se produjeron nuevas tramas subjetivas que se vieron interpeladas por desplazamientos políticos complejos. En efecto, durante esos años no solo se pasó de un régimen dictatorial a uno democrático - aunque este último cooptado por los enclaves autoritarios del primero_-, sino que se debió convivir con militares y civiles partícipes del régimen dictatorial en el parlamento y en la vida pública. A pesar de la creación de la Comisión Nacional de Verdad y Reconciliación en 1990 -que buscó esclarecer los casos de violaciones a los derechos humanos cometidos entre el 11 de septiembre de 1973 y el 11 de marzo de 1990- y otras instancias de derechos humanos similares, durante los primeros diez años de la post - dictadura chilena coexistieron silencios cómplices y expectativas frustradas de justicia (Erazo, Ramírez y Scantlebury 2011). 
Durante este proceso transicional, los hijos del golpe, aquellos nacidos a mediados de 1970 y durante la década de 1980, comenzaron a ingresar al paisaje social y cultural del Chile de los noventa como una nueva generación. Sin ser testigos directos del 11 , todos fueron protagonistas de sus consecuencias y efectos culturales. Si en los ochenta forjaron su infancia y los noventa experimentaron su adolescencia, durante el dos mil se inscribieron en la historia como adultos en proceso de formación. Como espectadores de la transición democrática, esta generación ha elaborado una producción artística que caracteriza por esbozar/discutir/ problematizar temas comunes: los proyectos biográficos, lo privado, lo contenido. Esta relación la podemos ver en variadas esferas y autores chilenos: en el cine, por ejemplo, en películas como 'En la cama' (2005) y 'La vida de los peces' (2010) de Matías Bize, o en la película 'Metro cuadrado' (2011) de Nayra Ilic o en 'Rabia' (2006) de Oscar Cárdenas, entre otras. En estas propuestas estéticas, la inauguración de la subjetividad posdictatorial se describe por una incubación hacia lo íntimo (Saavedra 2013).

En el caso de la literatura, este problema se muestra como un ejercicio recurrente y especialmente interesante en los trabajos de Alejandro Zambra (Santiago de Chile, 1975), quien se ha convertido en los últimos años en una figura renombrada en el espacio literario iberoamericano. En Chile, su figura ha logrado amplio reconocimiento y sus trabajos han sido vinculados a una narrativa generacional caracterizada por los paisajes literarios de la posdictadura chilena, así como también por los cambios culturales surgidos con la globalización. A lo largo de sus libros cortos (nouvelles), novelas y cuentos - Bonsái (2006), La vida privada de los árboles (2007), Formas de Volver a casa (2011), Mis documentos (2013) y Facsímil (2014)—, es posible advertir una insistencia por el repliegue hacia la esfera privada. Si bien sus historias se escriben desde la habitabilidad y sociabilidad urbana - y la historia chilena es un escenario siempre presente tanto en sus desdichas como en sus festividades - , podría decirse que estos se apropian de lo público para acumularlo en lo privado. Con ello, Zambra esboza insumos críticos para pensar el Chile contemporáneo. 
El presente artículo busca discutir los efectos de los procesos de neoliberalización en Chile en su literatura reciente. Al hacerlo, esboza una hipótesis sobre cómo se tematizó el habitar posdictatorial en los terrenos literarios y en los entramados culturales más generales. Así, a partir de la obra de Alejandro Zambra, es posible ilustrar y problematizar cómo su generación se caracteriza por la contención y el repliegue hacia lo íntimo. En vistas de aquello, y con base en un análisis sociológicocultural sobre la individuación de la sociedad actual (Yopo 2013), este artículo elabora dos ejercicios de lectura sobre los trabajos de Zambra: por una parte, sus pasajes escriturales se comprenderían por las figuras de la privatización biográfica bajo el neoliberalismo chileno, donde se encuentran especialmente sus primeras nouvelles Bonsái y La vida privada de los árboles. Por otra, su escritura también podría ser descrita como heredera de ciertas tesis del postrauma dictatorial chileno bajo las lógicas de la memoria: después de la catástrofe, sólo queda el repliegue reflexivo en lo privado. En esta categoría encontramos la novela Formas de volver a casa y el libro compilatorio de cuentos Mis documentos. Se propone inscribir la obra de Zambra en una generación escritural caracterizada por elaborar una estética de la contención. Al finalizar, y bajo el contexto de las movilizaciones estudiantiles de 2011, este artículo concluye con ciertas interpretaciones sobre las nuevas tematizaciones políticas, sociales y culturales de Chile en la última obra literaria de Zambra: Facsimil, de 2014.

\section{Modernidad(es) avanzadas e individuación}

La reflexión sociológica contemporánea ha señalado con insistencia la necesidad de diferenciar nuestra actual modernidad avanzada de una primera modernidad. Son múltiples las denominaciones disponibles para esta constatación: posmodernidad, radicalización de la modernidad, modernidad líquida, modernidad inconclusa, sociedad del riesgo, etc. (Beck, Giddens y Lash 1997). Independiente de esta estrategia disciplinar, lo cierto es que, a nivel cultural, los efectos de este proceso son evidentes (Bauman 2010). Durante gran parte del siglo $\mathrm{XX}$ ha existido un importante debate sobre las consecuencias subjetivas y sistémicas de este fenómeno. Para algunos, uno de los principales 
efectos de nuestra actual modernidad es la fragmentación del sujeto (e incluso su disolución); para otros en cambio, nuestro tiempo actual daría pie a un nuevo tipo de singularización (Beck y Beck - Gernsheim 2003). Esta supuesta contradicción ha significado un importante debate en los estudios culturales y sociales actuales.

En algunos niveles, la sociedad contemporánea se caracteriza por su creciente autonomización estructural y la ampliación acelerada de diversos esquemas subjetivos en el individuo (Bilbao 2007). Los componentes clásicos de integración se fragmentan (familia, Estado, instituciones, etc.) y las lógicas de sentido del individuo se vuelven cada vez más difusas. De la misma forma, la sociedad pierde todo referente colectivo y las formas de habitar en el mundo se vuelven autorreferentes e inestables. Esto tiene fuertes implicaciones en las experiencias y horizontes de expectativas de los individuos: por una parte, se vuelven precarios los recursos disponibles para construir los proyectos biográficos; pero, por otra, se fortalecen sus espacios de autorreflexión (Giddens 1997). En otras palabras, aun cuando la construcción de las identidades subjetivas y su coordinación con los sistemas e instituciones sociales se vuelven inestables, el individuo se ve compelido por la sociedad a reflexionar sobre su condición en el mundo, generando cierta búsqueda de sentido. Esta es, evidentemente, una de las mayores tensiones de la sociedad actual: los individuos administran y reflexionan sus proyectos biográficos (narraciones, identidades, etc.), pero éstos deben estar en función de las prácticas e instituciones sociales en permanente mutación.

Uno de los conceptos clave para comprender este proceso es el de individuación. Para Martucelli y Araujo, es posible describir la individuación como el proceso de dos caras a través del cual, por una parte, las sociedades al diferenciarse internamente reducen su pretensión y capacidad para servir de referentes globales para la definición de las identidades personales; por otra, las personas hacen descansar sobre sí mismas y sus elecciones la definición de sus identidades específicas y de sus proyectos de vida. En este sentido, es central comprender el individuo como el resultado de un modo específico de hacer sociedad (79). Esto significa que las determinaciones tanto estructurales como subjetivas 
de una sociedad configuran un modelo específico de individuo. Desde esta noción, todo proceso de transformación estructural en la sociedad implicará cambios en las narraciones biográficas y proyectos de vida.

Según la tesis de las múltiples trayectorias de la modernidad (Wagner 2010) existirían elementos comunes del proyecto moderno - y sus actuales características - que, sin embargo, y debido a la diversidad de componentes histórico-sociales, hacen posible la existencia e identificación de diversas modernidades. Esto significa que, en el caso de Latinoamérica, es posible vislumbrar una trayectoria propia a la modernidad, así como nuevas formas de subjetividad y organización institucional. Todo ello, por cierto, en un contexto donde todo se ve afectado por los procesos de la modernidad avanzada. No obstante, creemos que resulta difícil plantear una unidad regional Latinoamericana.

Las herencias sociales y culturales, y las recientes transformaciones económico — políticas (neoliberales) de cada país de la región —algunas promovidas bajo dictaduras militares-, complican la identificación de una "lógica común" en la era postmoderna (Beverley, Oviedo y Michael 1995). En este sentido, y aun cuando existen modelos teóricos que logran aunar estas diferencias - y suplirlas por categorías aparentemente comunes - , resulta cuestionable su rendimiento. Si bien se disponen de categorías compartidas regionales, no es menos cierto que las decisiones, instituciones, prácticas y complejidades político - nacionales históricas reproducen rasgos diferenciadores en las subjetividades y formas de construcción de sujetos. Esto obliga, por tanto, a denotar en todo análisis cultural actual, la importancia de las diferencias culturales potenciales en América Latina. Resulta entonces plausible analizar los procesos de individuación desde sociedades particulares como la chilena.

\section{The chilean way a la modernidad en la década de los noventa}

La trayectoria reciente de la modernización en Chile es sumamente productiva si la analizamos según los esquemas descritos. La sociedad chilena, luego del golpe militar de septiembre de 1973, cambia su organización social y subjetiva en forma dramática: son innumerables 
los estudios y reflexiones surgidas a partir de ese acontecimiento (Lechner 2002). Si bien la experiencia narrable bajo la dictadura militar tiene por sí sola una impronta clave para la sociedad chilena, es posible señalar que serán las consecuencias posteriores a ella donde se hará más evidente la transformación cultural del Chile actual (Garretón). Con el retorno a la democracia en 1989 y bajo el rótulo de transición democrática, la sociedad chilena necesitó establecer un nuevo referente/ relato de proyección histórica. Esto requirió, evidentemente, organizar un modelo societal que rigiera el país en las siguientes décadas. Bajo la herencia de las transformaciones neoliberales $-\mathrm{y}$ su rigurosa implementación - y el resguardo pactado entre militares y civiles, la sociedad chilena estableció un esquema de conducta basada en el miedo a lo político y la obediencia casi ciega a la economía.

Durante la década de los noventa, en Chile cohabitó un despliegue institucional democrático bajo un modelo económico neoliberal. En otras palabras, convivieron los procesos de instalación democrática -administrada desde los gobiernos de centro-izquierda de la "Concertación de Partidos por la Democracia" - y la implementación - iniciada y legitimada en un contexto de opresión - de un sistema radical de libre mercado. En ambos casos, los cuestionamientos sobre la legitimidad de estos procesos significaron, para la elite política y económica nacional, una prescindencia histórica. La sociedad chilena precisaba de un modelo de individuo que fuera proclive a insertarse y reconocerse en las nuevas reglas del entramado social. Con ello, la subjetividad comenzó a ser relegada a los subterráneos de la experiencia individual, superada por la conquista irremontable de la "nueva sociedad de mercado".

Provenientes principalmente de la sociología, en Chile emergieron tres miradas teóricas —entre otras - que han intentado explicar este nuevo fenómeno (económico, político y cultural) surgido en la década de los noventa y continuado en gran parte de los 2000. Uno de los trabajos de mayor importancia sobre el Chile de la "transición" es el escrito por Tomás Moulian. En Chile Actual. Anatomía de un mito, Moulian se enfoca en la configuración de un nuevo individuo: el ciudadano creditcard. Gracias a la expansión del mercado y la consolidación del sistema 
capitalista, los individuos de inicios de la década de los noventa se caracterizaron por su vocación impulsiva al consumo: "Este ciudadano creditcard es normalizado, "puesto en orden", regulado por el consumo con pago diferido. Tiene que subordinar sus estrategias de conflicto, a sus estrategias de sobrevivencia como asalariado. Ha aprendido que su futuro está en seguir siendo un trabajador creíble" (103). Nuevo tipo de ciudadano que Moulian entiende como una constatación estructural, es decir, donde las formas de subjetividad quedan replegadas al nuevo fundamento sistémico de la sociedad chilena.

Otra mirada teórica es la de Eugenio Tironi. Su libro La irrupción de las masas y el malestar de las élites. Chile en el cambio de siglo llegó a ser un best seller del análisis cultural donde destaca la década en cuestión por su espíritu orgulloso y optimista. A diferencia de la década anterior, los 90 significaron un "marcado individualismo centrado en el éxito económico y en el placer vehiculado por el consumo" (15). Tironi destaca como cambios culturales las formas del trabajo, las nuevas formas del consumo, la voluntad del consenso por sobre la del conflicto y la despolitización política, etc., y considera que Chile ha experimentado dos grandes procesos: por una parte, que en la década de los 90 los y las chilenas se volcaron hacia el futuro de un modo casi compulsivo (había, según él, un deseo evidente de mirar hacia delante). Y, por otra, "se consolidó un patrón de comportamiento mucho más individualista que el del pasado. Se confía en el propio esfuerzo como palanca de progreso, y eso ocurre en todos los grupos sociales, incluidos los más pobres" $(I d .18,19)$.

Otra de las aproximaciones elaboradas sobre la década de los noventa es la realizada por Jorge Larraín. En su libro Identidad Chilena, ofrece un análisis detallado sobre las configuraciones identitarias del Chile de posdictadura y describe tal periodo bajo la constatación de un discurso empresarial posmoderno. Este período, que tendría sus raíces en el régimen militar, se caracterizaría "por la prevalencia casi sin contrapeso de la visión y de las políticas neoliberales en economía" (162). Al igual que Moulian y Tironi, Larraín ve en las nuevas formas de consumo el germen de los cambios culturales recientes en Chile: despolitización, identidades fracturadas, pérdida del sujeto, desesperanza, etc.; a lo 
que denomina el "malestar de la cultura": junto con el dinamismo económico y este espíritu exitista del Chile de los 90, se ha levantado un sentimiento de desazón e inquietud y altos niveles de infelicidad. Sin embargo, Larraín señala un aspecto fundamental que surge bajo este nuevo fenómeno cultural: "La gente que ha sufrido cambios rápidos y dramáticos en su modo de vida puede experimentar sentimientos de confusión, desorientación y discontinuidad, pero raras veces se adapta a vivir en la contradicción y siempre trata de encontrar alguna coherencia personal" (Id. 152) De esta forma, si bien reconocemos la existencia de condiciones de fragmentación de la sociedad chilena bajo lógicas de la modernidad avanzada o postmoderna, no es menos cierta la constatación —en la nueva década del 2000 — del surgimiento de autorreflexión en el individuo con miras a la construcción de su proyecto biográfico. Aun cuando existen múltiples obstáculos para lograrlos, los individuos despliegan variadas estrategias reflexivas para definir sus identidades y proyectos de vida.

\section{Las figuras de la privatización biográfica en la obra de Alejandro Zambra}

Si en los noventa el relato optimista y triunfalista de la sociedad chilena posibilitó un nuevo tipo de individuo, en la década del 2000 las cosas cambiaron. Sin un relato común - mucho menos una voluntad fundacional que proponer-, la sociedad chilena se vio compelida a resignarse de su habitar en la historia. Si antes el consumo era un objetivo de vida, hoy, luego de haber satisfecho el placer del mismo, las búsquedas son distintas. Ya no se quiere acceder a esos bienes imposibles, sino que el individuo busca disponer de un horizonte de logro individual que cristalice esa capacidad. Así, la insatisfacción no es con la sociedad de consumo, sino con el proyecto biográfico de sus individuos.

Leonor Arfuch (2010), ha puesto en evidencia este problema en Argentina,

Consecuentemente con el afianzamiento de la democracia brotaba el democratismo de las narrativas, esa pluralidad de voces, identidades, sujetos y subjetividades, que parecían venir a confirmar las inquietudes de algunas teorías: la disolución de lo colectivo, de la idea misma de 
comunicad, en la miríada narcisística de lo individual (20)

Lo cierto es que desde la década del 2000 la constitución del problema biográfico ha tomado, al igual que en Argentina, un papel fundamental para comprender los nuevos cambios culturales. En este sentido, los soportes sociales de esta década insistieron en la necesidad de ser un individuo empoderado, pero ni el nivel institucional ni relacional aportó mucho para lograr ese proyecto. Cada individuo debía administrar, según sus recursos - económicos, culturales, sociales, etc. - su problema biográfico. Esto implicó, finalmente, reconocer la necesidad de autorreflexión en un contexto de incertidumbre mundial.

Como protagonistas de una derrota socialista y espectadores de una imposición de fuerza neoliberal, los chilenos han debido adaptarse en las últimas décadas a una ingeniosa retórica de desilusión neoliberal. Si a inicios de la década de 1970 el deseo de una sociedad otra era posible gracias a una articulación colectiva de subjetividades $-\mathrm{y}$ cuya generación se caracterizó por la "lucha en la unidad"-, en los 2000 todo ha mutado no solo hacia una proliferación de mercados de identidades, sino, sobre todo, al deseo permanente e insatisfecho de ser otro. Esto ha generado cierta tensión en el espacio biográfico de los individuos al exigirles reflexionar sobre ese alguien que no ha podido ser (Rojas 2013).

Bajo este escenario, ya no es posible manifestar un malestar de época. Lo que queda es, por el contrario, poner de manifiesto/develar ese hablar cínico sustentado en un cierto sentido común — que trae consigo un tiempo sin futuro-y sobrepoblar los paisajes del Chile posdictatorial con nuevos potenciales de subjetividad. Ante la amenaza de un agotamiento de aquellos potenciales, resulta necesario tensionar lo contemporáneo y pensar los detalles simples del cotidiano. En aquella línea de trabajo se ubican las dos primeras novelas cortas o cuentos largos de Alejandro Zambra.

Alejandro Zambra se ha convertido en los últimos años en una figura clave del espacio literario iberoamericano. En Chile, su figura ha logrado amplio reconocimiento y sus trabajos han sido vinculados a una narrativa generacional caracterizada por los paisajes literarios de la posdictadura chilena (Bottinelli 2016), así como por los cambios 
culturales surgidos con la globalización. Como ha señalado el filósofo Sergio Rojas,

En la narrativa de autores como Alejandro Zambra, Diego Zúñiga, Alejandra Costamagna, Nona Fernández, Leonardo Sanhueza, Lina Meruane, Álvaro Bisama, entre otros, encontramos una escritura en la que reconocemos tanto un afán de hacer memoria, como una voluntad de desmantelar la idea de la "gran historia". Se constituyen en cada caso subjetividades que se relacionan consigo mismas a partir de los relatos que despliega el trabajo de la memoria. Dicho de otra manera: el relato no acaece simplemente como el producto de un individuo que recuerda, sino como el médium de su autoconciencia. (Rojas 2015 239)

En Bonsái (publicada en 2006), es posible advertir esta forma de autoconciencia. La novela trata sobre dos estudiantes de literatura que, en su discurrir literario, establecen una relación intelecto-sentimental caracterizada por el deseo juvenil de descubrir y crecer juntos. Como habitantes de un territorio abierto a decisiones y vivencias infinitas, la relación se ve resquebrajada por las zozobras del cotidiano. Tras el quiebre, ambos realizarán sus proyectos biográficos en precariedad y en diferentes latitudes. Julio, el personaje principal, al perder un trabajo como transcriptor de una novela ajena, cuidará de un bonsái e intentará escribir una novela propia con el título del árbol japonés. Por su parte, Emilia emigrará a Madrid y vivirá una serie de experiencias difíciles como trabajadora e inmigrante latinoamericana.

Zambra anota, como una síntesis, esta historia:

La de Emilia y Julio fue una relación plagada de verdades, de revelaciones íntimas que constituyeron rápidamente una complicidad que ellos quisieron entender como definitiva. Ésta es, entonces, una historia liviana que se pone pesada. Ésta es la historia de dos estudiantes aficionados a la verdad, a fumar cigarrillos eternos, y a encerrarse en la violenta complacencia de los que se creen mejores, más puros que el resto, que ese grupo inmenso y despreciable que se llama el resto. Rápidamente aprendieron a leer lo mismo, a pensar parecido, y a disimular las diferencias. Muy pronto conformaron una vanidosa intimidad (Zambra 2018 24). 
Entre ambos se establece la construcción de un mundo distanciado de los otros: aquellos que caminan inmersos en sus propios entramados subjetivos. Sin embargo, en la medida en que avanza el relato, ambos personajes optan por la construcción de sus propios caminos vitales. Distanciados tanto territorial como emotivamente, Julio y Emilia ilustran la dificultad de coordinar expectativas recíprocas en un contexto dominado por horizontes estrechos. En el caso de Julio, el relato describe su deseo biográfico por constituirse en escritor y las dificultades que ello implica². De hecho, Zambra juega paródicamente entre el narrador y el personaje sobre aquello, propiciando lo que Silva señala como una metaficción, en el sentido de que expresa en su propio operar su autoconciencia de obra ficcional (Zambra 2018 11).

Bonsái es un libro corto, dividido en cinco secciones. Me interesa su idea general del bonsái. Más allá de su lógica de cuidado y mantenimiento riguroso, el bonsái es un árbol pensado para ser reprimido, controlado, podado, contenido. Es un árbol al que se le impide crecer, desparramarse, dispersarse. Es un árbol concebido para su apreciación privada en una pequeña maceta. Los personajes de Zambra son, en este sentido, agentes cuyas maniobras de acción son controladas según un regulado margen de posibilidades. Sus vidas, paisajes y experiencias se caracterizan por ser mundanas, sin mayores sobresaltos y con decepciones simples. El trasfondo histórico-político de Bonsái es tenue, casi imperceptible. Sin embargo, Bonsái propone algo más: develar los contornos de una generación de jóvenes contenida, que no explota, pero que está ahí, presente, inminente.

En un momento cualquiera, Julio decide dibujar algunos trazos de su vida reciente y compone, además de un cuerpo femenino - una referencia a Emilia y una nueva compañera sexual, María—, un bonsái. Luego de comprar un manual para su cuidado, el personaje principal lee la definición del árbol y medita sobre un aspecto clave: la palabra bonsái consiste tanto en el árbol vivo como en su recipiente, el macetero. Si el

\footnotetext{
${ }^{2} \mathrm{Al}$ respecto, se podría señalar que, en general, la obra de Zambra es un ejercicio literario que ayuda a comprender lo que la socióloga francesa Nathalie Heinich ha señalado como el "régimen de la singularidad" de los artistas, es decir, ese sistema de construcción social del autor-artista como excepcional, auténtico e increado (15).
} 
árbol en miniatura sale de él, entonces deja de llamarse bonsái. Luego, el narrador señala sobre las divagaciones de Julio:

'La selección de la maceta apropiada para un árbol es casi una forma de arte por sí misma', piensa y repite, hasta convencerse de que hay, allí, una información esencial. Se avergüenza, entonces, de Bonsái, su novela improvisada, su novela innecesaria, cuyo protagonista no sabe, ni siquiera, que la elección de una maceta es una forma de arte por sí misma, que un bonsái no es un árbol bonsái porque la palabra ya contiene al elemento vivo. Cuidar un bonsái es como escribir, piensa Julio. Escribir es como cuidar un bonsái, piensa Julio (Zambra 2018 80).

Así como una metáfora de la sociedad chilena, el bonsái es tanto una vida como un molde que la constriñe. En su unidad - indisoluble e inevitable - se constituye el desenvolvimiento biográfico. El árbol vivo puede crecer, desparramar sus raíces y levantar sus ramas y hojas. Sin embargo, aquel despliegue es posible solo con su estructura: su marco general de posibilidades (sociales). Bonsái, la novela, es entonces una metáfora de la contención vital en una sociedad posdictatorial como la chilena.

Algo similar ocurre con su segunda novela, La vida privada de los árboles (publicada en 2007). En sus páginas, Zambra despliega un mundo caracterizado por la espera. Todo transcurre en el hogar del protagonista y en una sola noche. En la novela, Julián distrae a la niña (Daniela) con "la vida privada de los árboles", una serie de historias que ha inventado para hacerla dormir. Durante toda la noche, él espera a Verónica, su pareja, mientras le narra cuentos a Daniela (quien es su hijastra) y reflexiona sobre su propia vida.

El narrador anota:

Tendido en la cama de la pieza blanca, Julián enciende un cigarro, el último, el penúltimo, o acaso el primero de una noche larga, larguísima, fatalmente destinada a repasar los más y los menos de un pasado francamente brumoso. De momento la vida es un lío que parece resuelto: ha sido invitado a una nueva intimidad, a un mundo donde le corresponde ser algo así como el padre de Daniela, la niña que duerme, y el marido de Verónica, la mujer que no llega, todavía, de su clase de dibujo. En adelante la historia se dispersa y casi no hay forma de continuarla (Zambra 2018 104). 
A diferencia de la novela Bonsái - por cierto, el árbol en miniatura es integrado como elemento narrativo al interior de La vida privada de los árboles - esta vez somos testigos de un reflexionar con el pasado y el presente, con los momentos de la infancia de Julián, y con relaciones afectivas truncadas. ¿Qué es la vida privada de los árboles? Más allá de ser una sumatoria de cuentos infantiles en la novela misma, Zambra propone una unión semántica entre un espacio estático/inamovible (el árbol) y un lugar privado, cerrado, íntimo (la vida privada) ${ }^{3}$. Bajo la espera de la llegada inminente de Verónica — que tarda sin razón aparente-, Julián va trazando episodios breves de su biografía como factores explicativos del presente. Expone, por ejemplo, que es hijo de una "familia sin muertos"; que durante su infancia pintaba los ladrillos de su casa con color "blanco invierno" y que, en 1984, al mirar por televisión los juegos olímpicos desarrollados en Los Ángeles, su mirada se concentró en la imagen de una jabalina por los aires. También recuerda jugar en familia al Metrópolis y escuchar a su madre tararear a Violeta Parra. En suma, recuerdos simples y cotidianos que corrían en paralelo a un país devastado por la represión política de Pinochet.

Durante La vida privada de los árboles Zambra elabora un experimento con las temporalidades biográficas. En sus páginas no solo se entrecruzan tiempos de infancia con vivencias del presente del protagonista, sino también historias fragmentadas de los personajes secundarios - todos femeninos - que recorren tanto su pasado como sus futuros. Así, en la sedimentación de relatos paralelos, Zambra va estableciendo ramificaciones aleatorias, donde lo privado y lo cotidiano se establecen como un telón de fondo simple, pero siempre en reconstrucción. Al finalizar la novela, el narrador deja entrever que Verónica no ha aparecido aquella noche. Por el contrario, nada se sabe de ella. Sin embargo, la vida continúa y los proyectos vitales se siguen escribiendo a pesar de las carencias y desapariciones.

Zambra termina su relato anotando:

\footnotetext{
${ }^{3}$ Esta idea también es posible de ser desarrollada a partir del título de la primera parte de la novela: "invernadero". Como se sabe, los invernaderos son espacios cerrados, protegidos y controlados para propiciar el crecimiento artificial de hortalizas $\mathrm{u}$ otros organismos vegetales.
} 
Llueve intensamente. A lo largo de siete cuadras, en un día de lluvia, es posible completar muchos diálogos. Durante cientos o miles de pasos, las palabras van y vienen, veloces, fugaces. Faltan diez minutos para las ocho de la mañana. Hace menos de una hora Julián decidió que el futuro debía comenzar. Éste es el día siguiente, pensó, y preparó café, y se lavó la cara, con especial pulcritud, refregándose una y otra vez, excesivamente, como si quisiera dañarse o borrarse. Luego gastó varios minutos construyendo la escenografía de una noche normal: desarregló las frazadas y las sábanas como si allí hubieran dormido dos personas, regresó a la cocina y sirvió dos tazas de café y bebió una y la mitad de la otra. Mascó una tostada y preparó un vaso de leche con chocolate para la niña (Zambra 2018 187)

Podríamos decir que La vida privada de los árboles es una novela bisagra: marca un desplazamiento reflexivo entre la problematización del tiempo presente (el ahora) y el pasado que aún parece difuso y lejano. Al mismo tiempo esboza elementos de un futuro impreciso, en construcción. Como ha señalado Areco, esta novela puede ser pensada como una representación de la intimidad a partir de la figura simbólica del acuario (10). Como una metáfora, el acuario en Zambra podría servir para pensar "una modalidad narrativa a la que podríamos llamar inicialmente novela de la intimidad que funciona como un dispositivo de vigilancia que mantiene a los personajes en el espacio cerrado y contaminado de la auto-observación" (Id. 16). De esta forma, y aun cuando La vida privada termina en un espacio abierto (la calle), el "imaginario espacial" del acuario nos ayuda a pensar los espacios de la intimidad y de la contención biográfica.

\section{Tesis del post- trauma dictatorial chileno}

Si bien las primeras obras de Zambra se pueden insertar en el paisaje privatizado del Chile neoliberal, sus dos últimos trabajos se han acogido a una cierta literatura de la memoria. Con base en esto, la novela Formas de volver a casa y el libro de cuentos Mis documentos sirven como insumos analíticos para explorar la memoria en Chile. Si bien Zambra no prescinde de su vocación contenida e intimista, en estas dos obras se constata un giro problemático. 
Formas de volver a casa es una novela que comienza y finaliza con un terremoto (evidencia de la fragilidad histórica de Chile). En sus páginas, Zambra explora las imágenes, sonidos, olores y paisajes de la dictadura militar, pero situado, históricamente, en la posdictadura tardía, es decir, del 2000. La novela trata de volver al hogar familiar ubicado en Maipú, la cuna de las ciudades satélites del Chile de los ochenta. En su retorno, escucha y analiza la vida de sus padres y su propia voz:

Ahora no entiendo bien la libertad de que entonces gozábamos. Vivíamos en una dictadura, se hablaba de crímenes y atentados, de estado de sitio y toque de queda, y sin embargo nada me impedía pasar el día vagando lejos de casa. ¿Las calles de Maipú no eran, entonces, peligrosas? De noche sí, y de día también, pero con arrogancia o con inocencia, los adultos jugaban a ignorar el peligro: jugaban a pensar que el descontento era cosa de pobres y el poder asunto de ricos, y nadie era pobre ni rico, al menos no todavía, en esas calles, entonces (Zambra 2011 23).

Los protagonistas de Zambra parecen vivir, tanto en su infancia como en su adultez, en un estado contradictorio: afuera del hogar se vive el terror, el miedo y la perplejidad, pero en su interior - en el hogar - todo pareciera acontecer en una aparente normalidad apolítica. Su familia no vive las pesadillas del acontecer dictatorial: solo lo viven los otros, los desconocidos, los anónimos. Y es ahí justamente donde se plasma una nueva lógica crítico-reflexiva. Como ha señalado Bieke Willem ${ }^{4}$,

En Formas de volver a casa se confirma en efecto algo que en las dos primeras novelas sólo es posible intuir: una emergente conciencia política, una nueva izquierda intelectual a la que se pide tolerancia con respecto al pasado, pero que refuta también enérgicamente las huellas reaccionarias de este pasado que parecen haberse anclado definitivamente en la sociedad chilena. El deseo de volver a casa de Zambra no es en absoluto una forma de embellecer el pasado. No obstante, conserva ese aspecto utópico, intrínseco de la nostalgia (Willem 2012 40).

\footnotetext{
${ }^{4}$ Willem señala la misma tesis en otro escrito: "Formas de volver a casa' va en contra de esta visión negativa de la nostalgia, reivindicando precisamente la responsabilidad personal (se dirige sobre todo a un gran grupo de chilenos supuestamente apolíticos) y la necesidad de la memoria." (Willem 2013 153)
} 
De esta manera, Formas de volver a casa permite contemplar el desconcierto que produce la acumulación histórica de experiencias silenciadas, contenidas y confusas. Al retornar a la infancia, Zambra intenta ganar tiempo no sólo para tematizar el pasado y comprender el presente, sino principalmente para buscar alternativas posibles de subjetivación en el Chile contemporáneo. Es ese awakening del que hablaba Walter Benjamín: es decir, ese volver al pasado para un nuevo resurgir político. Pero ese resurgir emerge desde y gracias a los tiempos de la inocencia: "la infancia es siempre quien encuentra las fuentes de donde mana la aflicción" (86).

A lo largo de Formas de volver a casa nuevamente se entrecruzan biografías en construcción. En ella aparecen familiares del protagonista, así como personajes misteriosos pero cercanos a los momentos simples del habitar cotidiano. Así, Claudia es para el protagonista, una excusa oportuna y necesaria para reconstruir el pasado. Además de vecina en la infancia y amante en la adultez, Claudia se constituye como un puente para "volver a casa". Gracias a ella el protagonista logrará recuperar las escenas de los personajes secundarios de una historia traumática reciente.

Al regresar de la casa de sus padres, en Maipú, el narrador describe:

Volvemos a casa y es como si regresáramos de una guerra, pero de una guerra que no ha terminado. Pienso que nos hemos convertido en desertores. Pienso que nos hemos convertido en corresponsables, en turistas. Eso somos, pienso: turistas que alguna vez llegaron con sus mochilas, sus cámaras y sus cuadernos, dispuestos a pasar mucho tiempo agotando los ojos, pero que repentinamente decidieron volver y mientras vuelven respiran un alivio largo. Un alivio largo pero pasajero. Porque en ese sentimiento hay inocencia y hay culpa, y aunque no podamos, aunque no sepamos hablar de inocencia o de culpa, dedicamos los días a repasar una lista larga que enumera lo que entonces, cuando niños, desconocíamos. Es como si hubiéramos presenciado un crimen. No lo cometimos, solamente pasábamos por el lugar, pero arrancamos porque sabemos que si nos encontraran nos culparían. Nos creemos inocentes, nos creemos culpables: no lo sabemos (Zambra 2011 137,138).

Formas de volver a casa se convierte así en un retorno problemático e incómodo. Recordar los pasajes —y paisajes — de los barrios de la 
infancia, los profesores de la escuela y la música de la adolescencia, sirven para elaborar una auto-interpelación compleja. Todos esos fragmentos biográficos que, en su momento eran utilitarios y perfectos, con los años se vuelven insumos para restructurar las convicciones o para reelaborar la propia historia del protagonista. En otros términos, para darle espacio a los recuerdos que reclaman su lugar en el presente. En palabras de Barraza y Plancarte, "como antihéroe caracterizado por la derrota, el personaje-náufrago de Formas de volver a casa lleva en su capacidad de resistencia la orgullosa aceptación de la derrota a través de "la evidencia de los hechos" en su aparente forma autobiográfica" (111). Así, la obra de Zambra se configura como una pulsión creativa a partir de un fracaso.

Lorena Amaro ha planteado que la pregunta incómoda por este "fracaso" puede leerse a través de la figura de la filiación. Para ella, el trabajo de Zambra aborda este problema al poner en tela de juicio la posición de los padres durante la dictadura militar desde una perspectiva infantil. Desde una mirada "a la distancia" (la adultez), los personajes de Zambra enfrentan su pasado deambulando entre un ir y venir al hogar de la infancia. Al juzgar su historia y la de sus padres, los personajes de la novela "intentan 'volver a casa', pero a una casa muy diferente de la real: intentan reconstruirse como una familia/comunidad que ha sido quebrantada. Habría que decir, pues, que la cuestión radica hoy en salir de casa" (Zambra 2011 126)

Este aspecto es replanteado en Mis documentos (publicado en 2013). En 11 cuentos, Zambra se desplaza narrativamente entre diversos paisajes culturales del Chile reciente. En cada uno de ellos, el autor despliega una serie de temáticas: el desencanto de los jóvenes de la transición democrática, las experiencias en la escuela durante los años ochenta, la vida en familia durante la dictadura militar y en el presente, separaciones amorosas, experiencias con la iglesia católica, las consecuencias de fumar, etc. Así como una sedimentación narrativa de la trayectoria de Zambra, Mis documentos se inscribe en la memoria del Chile actual como un archivo crítico del presente. En sus páginas no solo se van narrando procesos económicos, culturales, tecnológicos, políticos y sociales del Chile de las últimas tres décadas, sino también 
situaciones íntimas e irónicas que cruzan esos devenires históricos. En términos simples, en esta compilación de relatos se tematizan, poética y lúcidamente, los efectos e impactos de la globalización cultural. En sus páginas se desempacan carpetas "mis documentos" acumuladas por casi treinta años - por múltiples anónimos que están repletas de imágenes, apuntes, recuerdos, miradas y sensaciones.

En el relato "Recuerdos de un computador personal", Zambra explora cómo los chilenos de inicios de la década de 2000 gestionaron sus deseos y sueños a través del crédito de consumo. En 36 cuotas mensuales, Max —el personaje principal - había logrado comprar a sus 21 años de vida su primer computador. Sin conocer del todo su uso, y como un arqueólogo del presente, Max explora las funciones y posibilidades inéditas de Windows (como los grabadores de voz, sistema de organización de música, juegos pinball y buscaminas, etc.). Eso no solo le significó dejar de lado la guitarra, olvidar el dibujo y prescindir de la televisión, sino también reconocer una nueva temporalidad y cotidianidad frente a la pantalla. Claudia, su novia, repetirá el mismo patrón. Pero, para complementar el nuevo computador, adquiere una cámara fotográfica digital —otra compra a crédito - y comienza a organizar sus recuerdos y sueños junto a Max en carpetas y documentos:

Claudia pasó días ordenando esas imágenes — renombraba los archivos con frases tal vez demasiado largas, que solían terminar en signos de exclamación o puntos suspensivos, y enseguida las distribuiría en varias carpetas, como si correspondieran a viajes distintos, pero luego volvía a ponerlas todas juntas, pensado en que dentro de algunos años habría muchas carpetas, cincuenta, cien carpetas para las fotos de cien viajes futuros, pues deseaba una vida llena de viajes y fotografías (Zambra 2013 55).

Al igual que en Bonsái, el título del libro compilatorio ofrece elementos interesantes y complementarios a este relato. Mis documentos, como sabemos, remite a esa carpeta electrónica que viene por defecto en el sistema operativo. Todos tenemos una carpeta "Mis documentos" en nuestras computadoras. Es ahí donde se crean nuevas y más carpetas, se acumulan escritos terminados y en proceso, y se administran los archivos tanto personales como recopilados. En su interior se acumulan 
los registros electrónicos que servirán para una ocasión otra, futura, posible. Las carpetas sirven entonces como una metáfora de la vida posdictatorial en Chile: así como un gabinete de curiosidades del siglo XIX — que acumulaban y exhibían los fragmentos y detalles de múltiples fuentes y recorridos de vida de la burguesía y la realeza-, los documentos virtuales del siglo XXI sirven para resguardar casi al infinito los recuerdos e imágenes de los ciudadanos comunes. Gracias al desembarco del crédito y el libre mercado, Chile se tensionó entre aquellos que querían cerrar definitivamente las carpetas incómodas del pasado - la memoria obstinada - y dar paso al goce infinito del capitalismo, y entre los que insistían en recuperar esas carpetas, desempolvarlas y contar lo que ellas dicen (e interpelan) al presente.

Es justamente en esa última línea donde Zambra se sitúa. Como ha señalado Franken, las narraciones del escritor chileno nunca pierden la voz autorreflexiva sobre el presente conflictivo e incómodo. En sus palabras,

El "yo" de Formas de volver a casa y Mis documentos se siente bien y cómodo en el intento de representar a un "nosotros", a un colectivo que se siente identificado con los imaginarios sociales y con la literatura como espacio intocable y de elección. En la obra de Zambra, la posibilidad de una reconciliación afectiva del conflicto es factible, aunque éste persista (Franken 206)

En suma, tanto Formas de volver a casa como Mis documentos forman una unidad narrativa que discute tanto el espacio de experiencias - la historia de los personajes anónimos - como el horizonte de expectativas - su futuro - de una sociedad que reflexiona sobre las consecuencias del postrauma dictatorial chileno.

\section{Hacia una estética de la contención}

En las cuatro obras aquí analizadas es posible observar desplazamientos y continuidades narrativas. Existe, por cierto, un entrecruzamiento de lecturas en todas ellas y, en su conjunto, se podrían pensar como insumos de análisis de los procesos de individuación en Chile. En la producción escritural de Zambra vemos tanto los efectos 
de la privatización biográfica en la posdictadura, como evidencias de la reflexividad contemporánea bajo la sombra incómoda del trauma dictatorial chileno. En su obra hay una complementariedad entre ambas tesis y apuestas analíticas. Así, y con base en estos elementos, en las obras de Zambra se ofrecen evidencias para pensar — especular - una estética de la contención ${ }^{5}$.

En las novelas cortas y cuentos largos de Zambra, la ciudad, la calle y la historia se problematizan, en la mayoría de las veces desde el espacio privado o las instancias íntimas del cotidiano. Esas experiencias son podadas y regularizadas en Bonsái, o narradas y sostenidas desde un espacio estático e íntimo en La vida privada de los árboles. Pero también el pasado es discutido desde el ahora: hay un despertar incómodo en Formas de volver a casa, y un descubrimiento crítico en Mis documentos. Al igual que en otras esferas de acción del arte último en Chile, pareciera acontecer un registro rabioso de la imposibilidad del cambio político y social. En otros términos, la administración de los recursos representacionales y narrativos de Zambra refleja una contención de las preguntas incómodas, una contención de las dudas, una contención del grito rabioso acumulado.

En estos términos, la estética de la contención se expresa en formas visuales y escritas que denotan la consciencia de un pasado aún no agotado (siempre vigente e irritante) y la experimentación cotidiana de una permanente desilusión con un tiempo histórico cínico y neoliberal. En su conjunto, la estética de la contención problematiza la emergencia de un sujeto contenido, temeroso de expresar su impulso y deseo, de su ira: una generación, en definitiva, que se encuentra frenada, modelada para no sobrepasar los límites pero que, al mismo tiempo, no quiere olvidar y prescindir del problema histórico en cuestión. Justamente por su pertenencia irrevocable a una historia dramática — la dictadura y sus consecuencias culturales, políticas y económicas-, es que su esfuerzo se concentra en narrar y visualizar las contradicciones históricas de su tiempo. La generación de Zambra quisiera ser desborde, desorden y delirio. Sin embargo, aun cuando sigue siendo una generación incómoda

\footnotetext{
${ }^{5}$ Willem ha señalado, en una línea similar, que las novelas de Zambra se podrían denominar como "novelas del desarraigo" (Willem 2013 155) y, por su parte, Bottinelli como una "poética de la desposesión" (27).
} 
y en deuda con su tiempo, su despliegue poético y narrativo parece ser correcto, preciso, podado y profesional, no sucio ni rebelde.

Los hijos de la dictadura, aquellos nacidos entre mediados de 1970 y 1980, componen una generación que creció con el temor entre sus manos. Asumieron, en cierta medida, los designios del nuevo régimen neoliberal y establecieron un plan de vida con base en las posibilidades estructurales que la sociedad chilena le ofreció a inicios de 1990. Construido como sujeto y actuante en la posdictadura, en la década del 2000 sus narrativas comienzan a tematizar esta contención y esbozar sus características íntimas y cotidianas. De esta forma, esta estética de la contención podría definir los sentimientos, pasiones o impulsos refrenados de una generación que ha reservado su lucha y resistencia, al parecer, para sus sucesores biográficos. Desde el 2010 en adelante la historia nos sorprenderá.

El comienzo de la década de 2010 parecía una derrota para los partidos de la Concertación. Luego de 20 años de gobiernos de centroizquierda, el derechista Sebastián Piñera asumía la presidencia de Chile. Su equipo ministerial, conformado por empresarios y políticos vinculados al régimen militar, no haría presagiar lo que pasaría en sus años de gestión. No se puede afirmar directamente que la presencia de Piñera en el gobierno generó una radicalización de las posiciones críticas hacia el modelo de mercado imperante desde los tiempos de la dictadura. Sin embargo, el año 2011 sería reconocido como el año de las movilizaciones estudiantiles y sociales o, simplemente, del Chilean Winter (Villalobos-Ruminott 11,15). A las calles saldrían a manifestarse principalmente estudiantes con el slogan de "educación gratuita y de calidad", así como también demandas Mapuches, regionales, ecológicas, sexuales, etc. El comienzo de la década del 2010 vería una reactivación política y de movilización social nunca vista en la época democrática y liderada por una generación joven nacida en democracia.

Si la derrota de la Concertación significaba el cierre de un proceso posdictatorial, paradójicamente con la llegada de Piñera se daría inicio a un nuevo periodo de politización social (Programa de las Naciones Unidas para el Desarrollo (PNUD)). La movilización social, liderada por los estudiantes universitarios y secundarios, sería un hito clave para 
pensar lo político. Ciertamente, las movilizaciones y protestas pusieron en discusión nociones neoliberales tan arraigadas e incuestionables como la educación de mercado y la reducción del Estado. Con base en ello, la noción de derechos (derecho a una educación de calidad, derecho a la salud, derechos sexuales, derechos laborales y de pensiones, derechos culturales, etc.) amplió los márgenes de exigibilidad pública y permitió la desnaturalización de la sociedad de mercado. La idea era, en síntesis, pasar de una sociedad de consumidores a una sociedad de derechos.

Este descuadre del modelo neoliberal basado en la eficiencia y lo objetivo-racional abrió nuevas oportunidades de reflexividad y narrativa en Zambra. En su libro-experimento Facsímil (publicado en 2014) tematiza los nuevos tiempos del Chile actual y retoma una de las figuras simbólicas más reconocidas del modelo impuesto por la dictadura en materia educacional: la "Prueba de Aptitud Académica" (PAA), el test de ingreso a las universidades chilenas. A partir de una parodia al instrumento de medición — hoy reemplazado, aunque su símil mantiene la misma función: seleccionar a los mejores "preparados" para la educación superior ( $\mathrm{y}$, al mismo tiempo, exhibir las profundas desigualdades sociales y culturales que mantiene Chile)_, Zambra vuelve a tematizar cierta estética de la contención, pero con una postura anexada a los tiempos que corren.

A lo largo de las páginas de Facsímil, el autor chileno utiliza las selecciones múltiples - esos pequeños círculos que se debían llenar con lápiz grafito con la respuesta "correcta", impidiendo así toda interpretación o reflexión abierta sobre las preguntas y respuestascomo un recurso de reflexividad crítica de lo que le ha tocado vivir en su trayectoria educativa. Siguiendo el orden de la PAA ("Término excluido", "Plan de redacción", "Uso de ilativos", "Eliminación de oraciones" y "Comprensión de lectura"), Zambra va exponiendo diversas situaciones sobre Chile y su pasado y presente.

Tomando una cita de Pinochet, Zambra propone: 
Los estudiantes van la universidad a estudiar, no pensar.

$\begin{array}{llll}\text { a) } & \mathrm{a} & \mathrm{a} & \mathrm{a} \\ \mathrm{b}) & \mathrm{a} & \mathrm{a} & \mathrm{a} \\ \text { c) } & \mathrm{a} & \mathrm{a} & \mathrm{a} \\ \text { d) } & \mathrm{a} & \mathrm{a} & \mathrm{a} \\ \text { e) } & \mathrm{a} & \mathrm{a} & \mathrm{a}\end{array}$

(Zambra 2014 37,38)

Y complementa para el Chile actual:

$Y$ si les quedan , para eso está

esperanzas

la realidad

frustraciones

el copete (bebida alcohólica)

ilusiones

el vacío

piedras

la policía

neuronas

la pasta base (de cocaína)"

(Zambra 2014 38)

En ¿Qué es lo contemporáneo? Giorgio Agamben señala que puede decirse contemporáneo solamente quien no se deja enceguecer por las luces del siglo y alcanza a vislumbrar en ellas la parte de la sombra, su íntima oscuridad [...] el contemporáneo es aquel que percibe la oscuridad de su tiempo como algo que le concierne y no deja de interpelarlo (39). Con base en esto, Zambra no quiere descansar en la alfombra roja/pasarela del tiempo histórico chileno: el triunfo cínico neoliberal. Si bien en sus comienzos las luces del pasar simplista y el tedio cotidiano tomaron su atención, sus actuales trabajos denotan un giro alimentado por la pregunta incómoda del pasado y las sombras del hoy. Sus pasajes narrativos y paisajes históricos alcanzan a vislumbrar la parte sombría del Chile contemporáneo, su íntima oscuridad. Pero lo hace aún con una mirada contenida o, mejor dicho, con una rabia contenida que, aun cuando no lo creemos totalmente, aparentemente viene por defecto en el sistema operativo de su/nuestra generación. Es de esperar que la próxima generación, la hoy en operación, produzca 
su propia narrativa basada en una interpelación a la estética de la contención.

\section{Referencias}

Agamben, Giorgio. What is an apparatus? And other essays. California: Stanford University Press, 2009. Impreso.

Amaro, Lorena. Estéticas de la intimidad. Santiago de Chile: Pontificia Universidad Católica de Chile, 2009. Impreso.

Areco, Macarena. «Imaginario espacial en la narrativa chilena reciente: El acuario como representación de la intimidad en relatos de Contreras, Zambra y Bolaño.» Alpha (2014): 9-22. Impreso.

Arfuch, Leonor. El espacio biográfico. Dilemas de la subjetividad contemporánea. Buenos Aires: FCE, 2010. Impreso .

Barraza, Luisa y María Plancarte. «Memoria y naufragio en Formas de volver a casa de Alejandro Zambra.» Revista de Literatura, Teoría y Crítica (2016): 99-112. Impreso.

Bauman, Zygmunt. La globalización. Consecuencias humanas. México: FCE, 2010. Impreso.

Beck, Ulrich y Elizabeth Beck-Gernsheim. La individualización: el individualismo institucionalizado y sus consecuencias sociales y politicas. Barcelona: Editorial Paidós, 2003. Impreso.

Beck, Ulrich, Anthony Giddens y Scott Lash. Modernización reflexiva: política, tradición y estética en el orden social moderno. España: Alianza Editorial, 2003. Impreso.

Benjamin, Walter. Denkbilder. Imágenes que piensan. Madrid: Abada Editores, 2014. Impreso.

Beverley, John, José Oviedo y Aronna Michael. The postmodernism debate in Latin América. Duke University Press, 1995. Impreso.

Bilbao, Andrés. Individuo y orden social. La emergencia del individuo y la transición a la sociología. Madrid: Ediciones Sequitur, 2007. Impreso.

Blanco, Fernando. Desmemoria y Perversión: Privatizar lo público, mediatizar lo intimo, administrar lo privado. Santiago de Chile: Editorial Cuarto Propio, 2010. Impreso.

Bottinelli, Alejandra. «Narrar (en) la 'post': la escritura de Álvaro Bisama, Alejandra Costamagna, Alejandro Zambra.» Revista Chilena De Literatura (2016): 7-31. Impreso. 
Erazo, Ximena, Gloria Ramírez y Marcia Scantlebury. Derechos humanos, pedagogía de la memoria y políticas culturales. Santiago de Chile: Editorial Lom, 2011. Impreso.

Franken, María Angélica. «Memoria e imaginarios de formación de los hijos en la narrativa chilena reciente.» Revista Chilena de Literatura (2017): 187-208. Impreso.

Garretón, Manuel Antonio. La sociedad en que vivi(re)mos. Introducción sociológica al cambio de siglo. Santiago de Chile: Editorial Lom, 2000. Impreso.

Giddens, Anthony. Modernidad e identidad del yo: el yo y la sociedad en la época contemporánea. España : Ediciones Península, 1997. Impreso.

Heinich, Nathalie. Lo que el arte aporta a la sociología. México : Conaculta, 2001. Impreso .

Larraín, Jorge. Identidad Chilena. Santiago de Chile: Editorial Lom, 2001. Impreso.

Lechner, Norbert. as sombras del mañana: la dimensión subjetiva de la política. Santiago de Chile: Editorial Lom, 2002. Impreso.

Martuccelli, Danilo y Kathia Araujo. «La individuación y el trabajo de los individuos.» Educação e Pesquisa 36 (2010). Impreso.

Moulian, Tomás. Chile actual. Anatomía de un mito. Santiago de Chile: Editorial Lom, 1997. Impreso.

Programa de las Naciones Unidas para el Desarrollo (PNUD). Informe sobre Desarrollo Humano en Chile 2015. Los tiempos de la politización. Santiago de Chile: PNUD, 2015. Digital .

Rojas, Sergio. La sobrevivencia cínica de la subjetividad. Santiago de Chile: Cuadro de Tiza, 2013. Impreso .

- «Profunda superficie: memoria de lo cotidiano en la literatura chilena.» Revista Chilena De Literatura 89 (2015): 231-256. Impreso.

Saavedra, Carlos. Intimidades desencantadas. La poética cinematográfica del dos mil. Santiago de Chile: Editorial Cuarto Propio, 2013. Impreso.

Tironi, Eugenio. La irrupción de las masas y el malestar de las élites. Chile en el cambio de siglo. Santiago de Chile: Editorial Grijalbo, 2000. Impreso.

Villalobos-Ruminott, Sergio. «The chilean Winter.» Radical Philosophy (2012): 11-15. Impreso.

Wagner, Peter. «Multiple Trajectories of Modernity: Why Social Theory Needs Historical Sociology.» Thesis Eleven 100.1 (2010): 53-60. Impreso.

Willem, Bieke. «Desarraigo y nostalgia. El motivo de la vuelta a casa en tres novelas chilenas recientes.» Iberoaméricana (2013): 139-157. Digital. 
—. «Metáfora, alegoría y nostalgia: La casa en las novelas de Alejandro Zambra.» Acta literaria (2012): 25-42. Impreso.

Yopo, Martina. «Individualización en Chile: Individuo y sociedad en las transformaciones culturales recientes.» Revista Psicoperspectivas 12.2 (2013): 4-15. Digital. <https://scielo.conicyt.cl/pdf/psicop/v12n2/art02.pdf >.

Zambra, Alejandro. Bonsái \& La vida privada de los árboles. Barcelona: Anagrama, 2018. Impreso.

—. Facsímil. Santiago de Chile: Hueders, 2014. Impreso.

-. Formas de volver a casa. Barcelona: Anagrama, 2011. Impreso.

—. Mis documentos. Barcelona: Anagrama, 2013. Impreso. 